\title{
Early Weanling and Precocious Development of Small Intestine in Rats: Genetic, Dietary or Hormonal Control
}

\author{
P. C. LEE ${ }^{(25)}$ AND EMANUEL LEBENTHAL \\ Division of Gastroenterology and Nutrition, Children's Hospital, SUNY at Buffalo, Buffalo, New York, USA
}

\begin{abstract}
Summary
Small intestinal development was followed in rats from 17 to 28 days of age in order to evaluate the interactions of diets, genetic preprogramming, and hormones in influencing developmental changes. Control pups, weaned naturally at 21-24 days, showed a gradual increase in body weight, intestinal length, and segmental mucosal weight, total DNA, and protein content. In contrast, pups weaned at 17 days showed an immediate increase in intestinal length, decrease in lactase, and precocious increase in sucrase and maltase. The changes in segmental mucosal weight, DNA and protein contents, however, paralleled that of controls. Pups nursed up to 25 days had a smaller body weight, shorter intestine, lighter mucosa, and lesser mucosal protein content. They showed no significant delay in the increase in sucrase and maltase together with a persistent higher level of lactase. Enterokinase and leucine aminopeptidase showed little change irrespective of the dietary modifications. Significant increases in segmental mucosal mass, DNA, and protein contents during the studied period were seen in all animals. At 19 days, early weaned pups had serum levels of corticosteroids about 3 times that of control or prolonged nursed pups. The results support the concept of an inherent biologic program as a basic control of intestinal ontogeny whereas dietary changes seem to have a modifying role and act directly, or in concert with, hormonal changes.
\end{abstract}

Neonatal rats have no detectable sucrase, low maltase, and high levels of lactase activities in their small intestines. The activities of sucrase and maltase increase abruptly about the 15th day of age. These two enzymes continue to rise during the third and fourth week with a concomitant decrease in lactase. The third week of life in rats corresponds to the weaning time that is marked by a shift from a fat-rich diet supplied by the mother (4) to a carbohydrate-rich lab-chow diet. The carbohydrate is also changed from an almost exclusive lactose-containing milk to a predominant glucose-polymer- and sucrose-containing chow. A casual relationship exists therefore between dietary changes and the increase in sucrase and maltase with a corresponding decrease in lactase. The possibility of a "dietary influence" of enzymes is further strengthened by the observations that sucrase rises precociously by early feeding of sucrose $(15,21)$. In addition, we have shown (16) that prolonged nursing leads to a slower decline in lactase activity. At 25 days of age, prolonged nursed rats show similar maltase and sucrase activities as control weaned rats. Similar studies by Henning and Guerin (20) also showed no depression in sucrase activities when pups were weaned onto a special diet with lactose as the sole source of carbohydrate. These results are in agreement with those studies using intestinal explants $(8,11)$ or in vitro cultures (6) and together suggest that the postnatal increase in sucrase and maltase in the rat is preprogrammed. Other studies have shown that hormones, particularly corticosteroids, also play a role in the development of disaccharidase in these animals (13,
14); however, its relationship to diet has been explored only to a limited extent $(1,10,15,21)$.

In order to reexamine the interactions among genetic preprogramming, dietary, and hormonal changes, as controlling factors in the development of the brush border enzyme during the weaning period, we studied: (1) the sequential development of the small intestine, with emphasis on the brush border enzymes; (2) the effect of prolonged nursing and early weaning on the development of sucrase, maltase, lactase, enterokinase, and leucine aminopeptidase; and (3) the possible involvement of corticosteroids in early weaning as one of the regulatory determinants.

\section{MATERIALS AND METHODS}

Animals. Pregnant mothers of Sprague-Dawley rats were obtained commercially on the 15th day of gestation and housed individually with a $12 \mathrm{~h}$ light-dark cycle. The day of birth was taken as day 0 . At day 1 , all pups were removed, pooled, and redistributed such that each mother had 12 pups (normal litter size, 14-16). Each mother with her group of pups was housed separately. Dams were fed laboratory chow (Wayne Lab Blox, Allied Mills, Inc., Chicago, IL) and water ad libitum until day 17 when experiments began.

Procedures. At day 17, pups were removed, pooled, and separated into three groups. Group 1. Control weaning, dams and her pups were allowed to stay together such that both mother and pups had access to chow and water. Group 2. Early weaning, pups were separated from dams and fed powdered chow during the next 3 days followed by regular chow pellets thereafter. Group 3. Prolonged nursing, pups were prevented from access to chow. Two sets of dams were used; one set was allowed to feed in a separate cage while the second set was nursing. The two sets of dams were exchanged every $6 \mathrm{~h}$ for alternate feeding and nursing.

Preparation of mucosal homogenate. At 17, 19, 22, and 25 days of age, rats (from three to five) from each group were killed. For groups 1 and 2, experiments were carried out further to 28 days. The whole intestine (from the pyloric end to the ileal-caecal region) was removed and trimmed of fat and mesentery. The length of the intestine was measured by attaching a $5 \mathrm{~g}$ weight to one end. A $10-\mathrm{cm}$ length was removed from the proximal end representing the duodenal segment. Another $10-\mathrm{cm}$ length was obtained from the $20-30 \mathrm{~cm}$ stretch which was taken as the jejunal segment. Each segment was split and the intestinal content was removed by gently wiping with tissue paper. The mucosa was scraped and weighed separately. The mucosal preparation from each segment was separately homogenized with a Potter-Elvehjem homogenizer using a teflon pestle with the vessel immersed in crushed ice. Homogenates obtained were used for the determination of DNA, protein, lactase, maltase, sucrase, enterokinase, and leucine aminopeptidase.

Biochemical determinations. Protein was determined by the techniques of Lowry et al. (17) using bovine serum albumin fraction $\mathrm{V}$ as the standard. DNA was first precipitated with cadmium 
chloride and then measured by the calorimetric reaction with diphenylamine reagent according to Burton (2) who used highly polymerized calf thymus DNA as the standard.

Maltase, lactase, and sucrase activities were assayed by the method of Dahlqvist (5), which uses maltose, lactose, and sucrose as the corresponding substrate. Disaccharidase activities were expressed as $\mu$ mole of disaccharides hydrolyzed per min per $g$ of protein.

Enterokinase activity was assayed in two steps. The mucosal homogenate was preincubated with trypsinogen and aliquots of the incubation mixture were then determined for trypsin formed. Trypsin activity was assayed according to the method of Erlanger et al. (7) using benzoyl-D, L-arginine- $p$-nitroaniline as the substrate. Activity was expressed as $\mu$ mole of substrate hydrolyzed per $g$ protein.

Leucine aminopeptidase activity was assayed by the method of Szasz (23) using L-leucine-p-nitroanilide as the substrate. The activity was expressed as $\mu$ mole of substrate hydrolyzed per min per $g$ of protein. All animals were sacrificed at $0900-1000 \mathrm{~h}$. Pooled serum samples obtained from pups of each group at day 19 were sent to Endocrine Sciences (Tarzania, California) for the determination of corticosteroid levels. The method used employed a direct radioimmunoassay technique with an antiserum specific for corticosterone. Interference by cortisol was found to be minimal.

Statistics. All results are presented as mean \pm S.E. Difference between mean of experimental and control groups were evaluated by unpaired Student's $t$ test with $P<0.05$ considered as significant.

\section{RESULTS}

Table 1 summarizes the developmental changes in body weight and some sommatic parameters of the small intestine. Early weaning did not affect the body weight. Prolonged nursing led to a decrease in the body weight by day 22 . Early weaning promoted elongation of the intestine, which reached a length longer than that of controls at days 19 and 22 . On the other hand, prolonged nursing prevented the increase in intestinal length; at 25 days, the intestine was significantly shorter than that of the control. Changes in segmental mucosal wet weight in the early weaned group closely paralleled that of the controls. Prolonged nursing led to a decrease in mucosal mass in jejunal segment at day 22 and in both duodenal and jejunal segments at day 25 . Total protein in duodenal and jejunal mucosa generally reflected the changes in the mucosal mass. Early weaning or prolonged nursing did not alter the increase in segmental mucosal DNA content with age (not shown).

Both early weaning and prolonged nursing affected the devel- opment of the mucosal enzymes (Fig. 1). In both duodenal and jejunal segments, early weaning led to a sharp increase in sucrase and maltase concentrations to a level far higher than found in any age group including the adults but a decrease in lactase concentration at 19 days of age. Increases in levels of maltase and sucrase then tapered off at day 22 but they were still higher than the control group. The tapering off continued in the early weaned group with a corresponding increase in the control group such that they reached similar levels at day 25 . The decrease in lactase in the meantime continued. In the early weaning group, lactase reached a low level comparable to that of adults at day 22 whereas the same enzyme in the control group did not drop to the same level until day 25 . In the prolonged nursing group, a significant delay in the decrease of lactase was evident such that at day 25 , the level was still 3-4 times that of the control. In spite of this delayed developmental changes in lactase, there was no significant delay in the developmental increase of sucrase and only minimal delay with maltase.

In the same mucosal specimens from both duodenal and jejunal segments, the concentrations of enterokinase and leucine aminopeptidase showed little developmental changes except for the slight increase in leucine aminopeptidase with the advance of age (Fig. 2).

The characteristic proximal-distal distribution of both enzymes were also maintained in all three groups at all ages studied (Figs. 1 and 2).

The segmental contents of these brush-border enzymes closely reflected the enzyme concentrations in the control and early weaned rats (Figs. 3 and 4). In the prolonged nursed rats, there were general reductions in segmental enzyme contents as compared to control rats; for sucrase, in both jejunal and duodenal segments at days 22 and 25; for maltase, in both segments at days 19, 22, and 25; for enterokinase, in both segments at day 25; for leucine aminopeptidase in jejunal segment at day 22 and duodenal segment at day 25 .

Table 2 summarizes the serum corticosteroid levels in the three groups of rats at day 19. The level from the nursing group showed a slight but insignificant increase compared to the control group. In contrast, the level for the early weaning group was almost 3 times that of the control.

\section{DISCUSSION}

Postnatal development of the rat small intestine is characterized by significant increases in mass, DNA, and alpha-glucosidases contents around 17-21 days of age (3). Because these changes coincide with the time of weaning, it has been implied that this

Table 1. Effect of early weanling and prolonged nursing on the developmental changes in body weight, intestinal length, segmental (10 $\mathrm{cm}$ ) mucosal weight and protein content in duodenal and jejunal segments of the small intestine

\begin{tabular}{|c|c|c|c|c|c|c|c|c|}
\hline \multirow{2}{*}{$\begin{array}{l}\text { Age } \\
\text { (days) }\end{array}$} & \multirow{2}{*}{$\begin{array}{c}\text { Number of } \\
\text { rats }\end{array}$} & & \multirow{2}{*}{$\begin{array}{l}\text { Body weight } \\
(\mathrm{g})\end{array}$} & \multirow{2}{*}{$\begin{array}{l}\text { Intestinal length } \\
(\mathrm{cm})\end{array}$} & \multicolumn{2}{|c|}{$\begin{array}{c}\text { Mucosal wet weight } \\
\text { (mg) }\end{array}$} & \multicolumn{2}{|c|}{$\begin{array}{l}\text { Protein content } \\
\quad(\mathrm{mg})\end{array}$} \\
\hline & & & & & Duodenal & Jejunal & Duodenal & Jejunal \\
\hline 17 & (10) & & $30.0 \pm 0.7^{2}$ & $54.6 \pm 1.6$ & $74.0 \pm 9.6$ & $49.4 \pm 26.4$ & $9.7 \pm 0.6$ & $7.0 \pm 1.0$ \\
\hline \multirow[t]{3}{*}{19} & (13) & $\mathrm{C}^{1}$ & $36.3 \pm 1.1$ & $57.8 \pm 1.7$ & $75.4 \pm 8.9$ & $60.0 \pm 8.6$ & $10.8 \pm 1.6$ & $7.9 \pm 1.2$ \\
\hline & (15) & EW & $34.1 \pm 1.4$ & $63.2 \pm 1.8^{4}$ & $91.3 \pm 10.1$ & $63.3 \pm 7.0$ & $13.4 \pm 1.4$ & $7.9 \pm 0.9$ \\
\hline & (11) & PN & $36.6 \pm 1.3$ & $57.8 \pm 1.2$ & $71.8 \pm 7.1$ & $61.8 \pm 7.5$ & $10.9 \pm 1.2$ & $7.4 \pm 1.2$ \\
\hline \multirow[t]{3}{*}{22} & (6) & $\mathrm{C}$ & $49.7 \pm 2.0$ & $75.5 \pm 5.0$ & $161.7 \pm 17.9$ & $130.0 \pm 11.6$ & $24.0 \pm 2.1$ & $18.4 \pm 2.2$ \\
\hline & (6) & EW & $47.7 \pm 3.1$ & $86.3 \pm 3.9^{4}$ & $175.0 \pm 19.7$ & $141.6 \pm 11.0$ & $23.1 \pm 2.3$ & $18.0 \pm 1.8$ \\
\hline & (7) & PN & $41.5 \pm 2.3^{3}$ & $66.7 \pm 1.3$ & $122.8 \pm 14.2$ & $82.9 \pm 19.3^{3}$ & $18.5 \pm 2.6^{3}$ & $12.8 \pm 2.3^{3}$ \\
\hline \multirow[t]{3}{*}{25} & (9) & C & $60.2 \pm 1.8$ & $84.4 \pm 2.1$ & $145.0 \pm 14.1$ & $125.5 \pm 10.6$ & $22.3 \pm 2.6$ & $15.1 \pm 1.1$ \\
\hline & (9) & EW & $59.2 \pm 2.2$ & $87.7 \pm 2.0$ & $158.8 \pm 11.4$ & $144.0 \pm 17.0$ & $21.0 \pm 0.8$ & $18.1 \pm 1.7$ \\
\hline & (8) & $\mathrm{PN}$ & $47.6 \pm 3.3^{3}$ & $67.0 \pm 3.1^{3}$ & $110.0 \pm 15.7^{3}$ & $82.9 \pm 10.1^{3}$ & $15.8 \pm 2.4^{3}$ & $11.3 \pm 1.6^{3}$ \\
\hline \multirow[t]{2}{*}{28} & (7) & C & $72.2 \pm 1.3$ & $98.9 \pm 2.8$ & $194.3 \pm 25.3$ & $167.0 \pm 37.1$ & $24.8 \pm 3.6$ & $19.9 \pm 4.5$ \\
\hline & (6) & EW & $73.5 \pm 2.0$ & $100.6 \pm 3.2$ & $201.6 \pm 40.0$ & $156.7 \pm 33.5$ & $26.1 \pm 5.8$ & $19.8 \pm 4.2$ \\
\hline
\end{tabular}

${ }^{1} \mathrm{C}$, Control; EW, early weanling; and PN, prolonged nursing.

${ }^{2}$ Values represent mean \pm S.E. of all results from animals of the same group. Individual specimen for each animal was assayed separately.
${ }^{3}$ Significantly less than control $(P<0.05)$.

${ }^{4}$ Significantly higher than control $(P<0.05)$. 


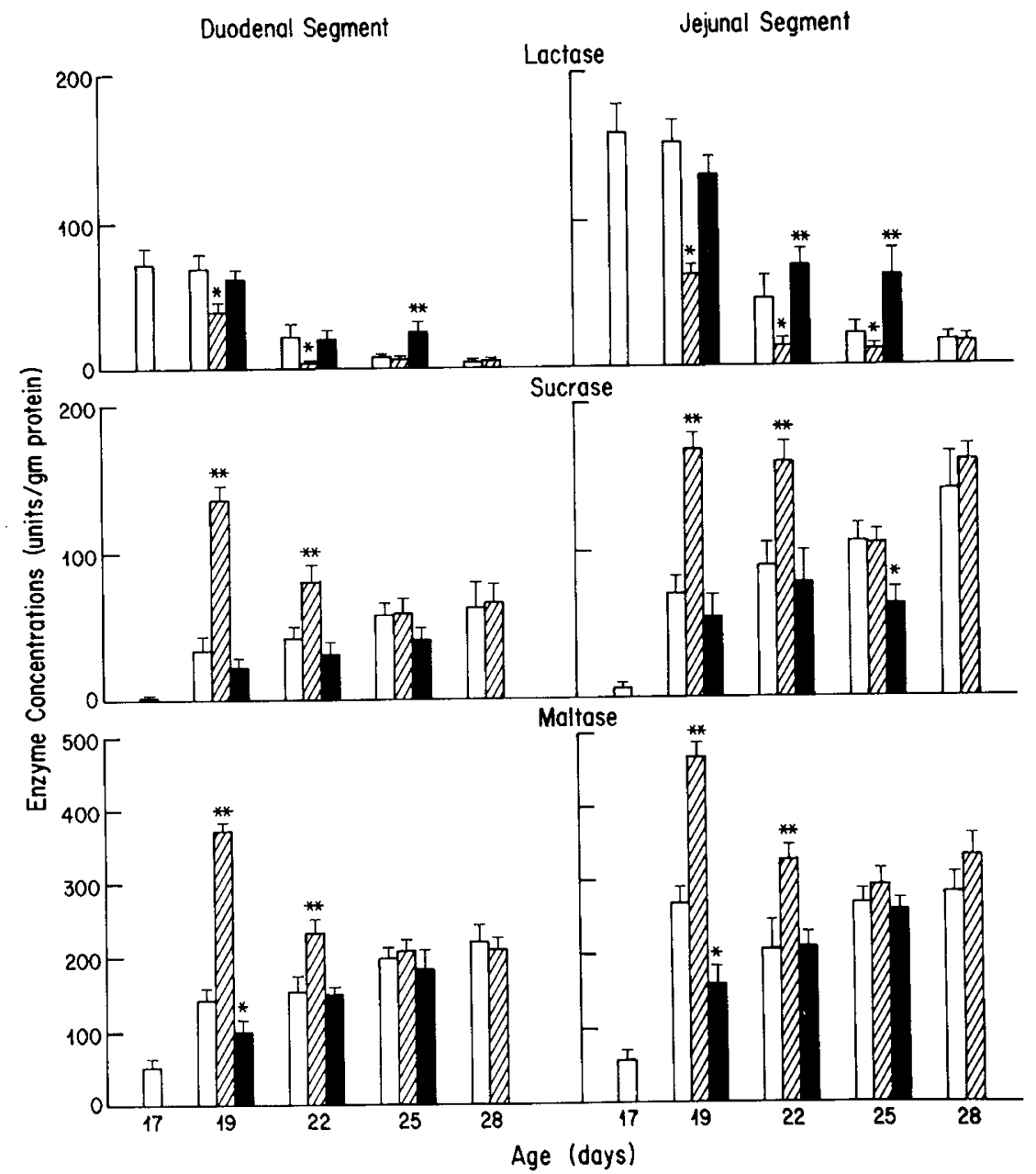

Fig. 1. Effect of early weaning and prolonged nursing on the developmental changes of lactase, sucrase, and maltase concentrations in mucosa from duodenal and jejunal segments of small intestine from weanling rats. Heights of bar represent the mean of results from all animals from the same age and group. Open bar, control; shaded bar, early weanling; and solid bar, prolonged nursing. Lines on top of bars represent S.E. (Asterisk) represents values significantly higher than control values and $\left({ }^{* *}\right)$, values significantly lower than control values $(P<0.05)$.

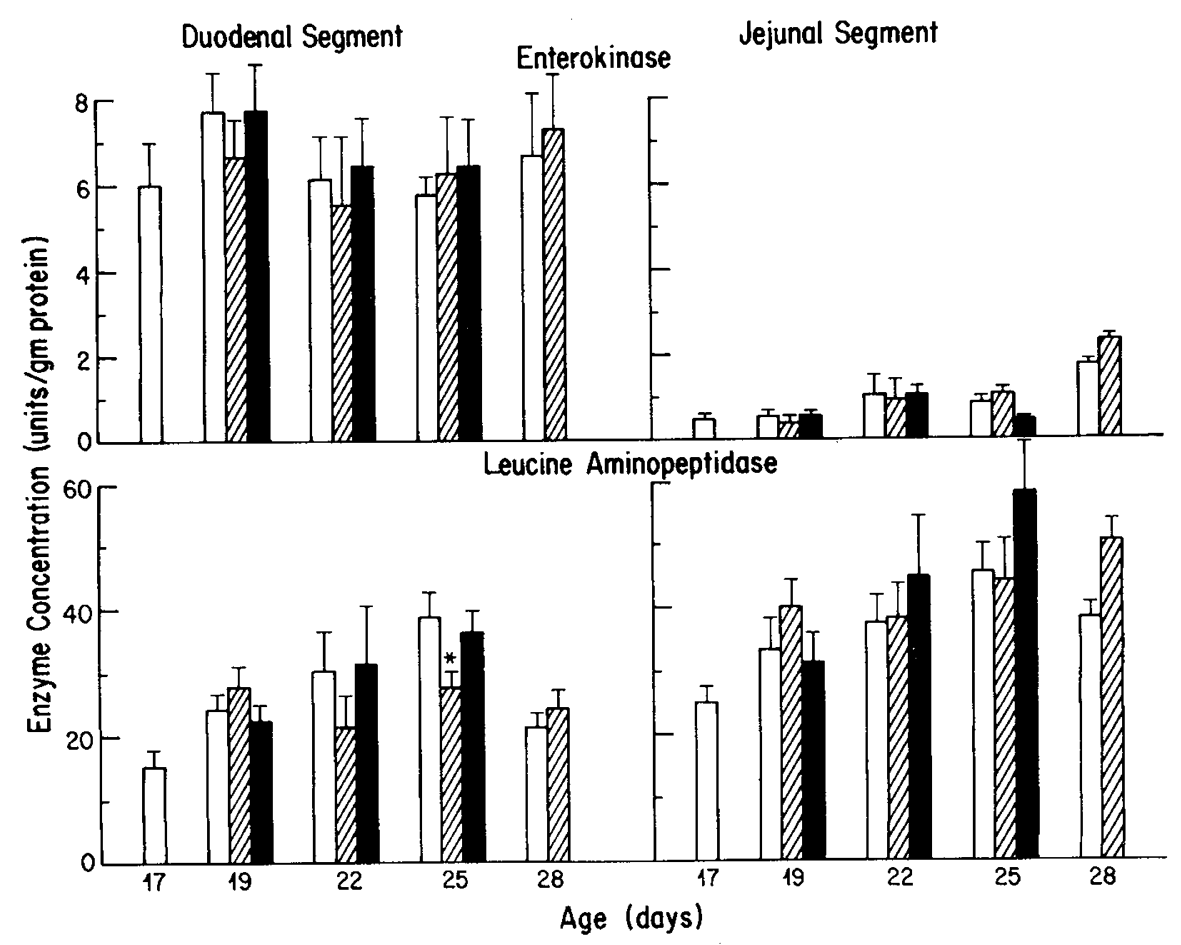

Fig. 2. Effect of early weaning and prolonged nursing on the developmental changes of enterokinase and leucine aminopeptidase concentrations in mucosa from duodenal and jejunal segment of small intestine from weanling rats. All symbols are the same as in Figure 1. 


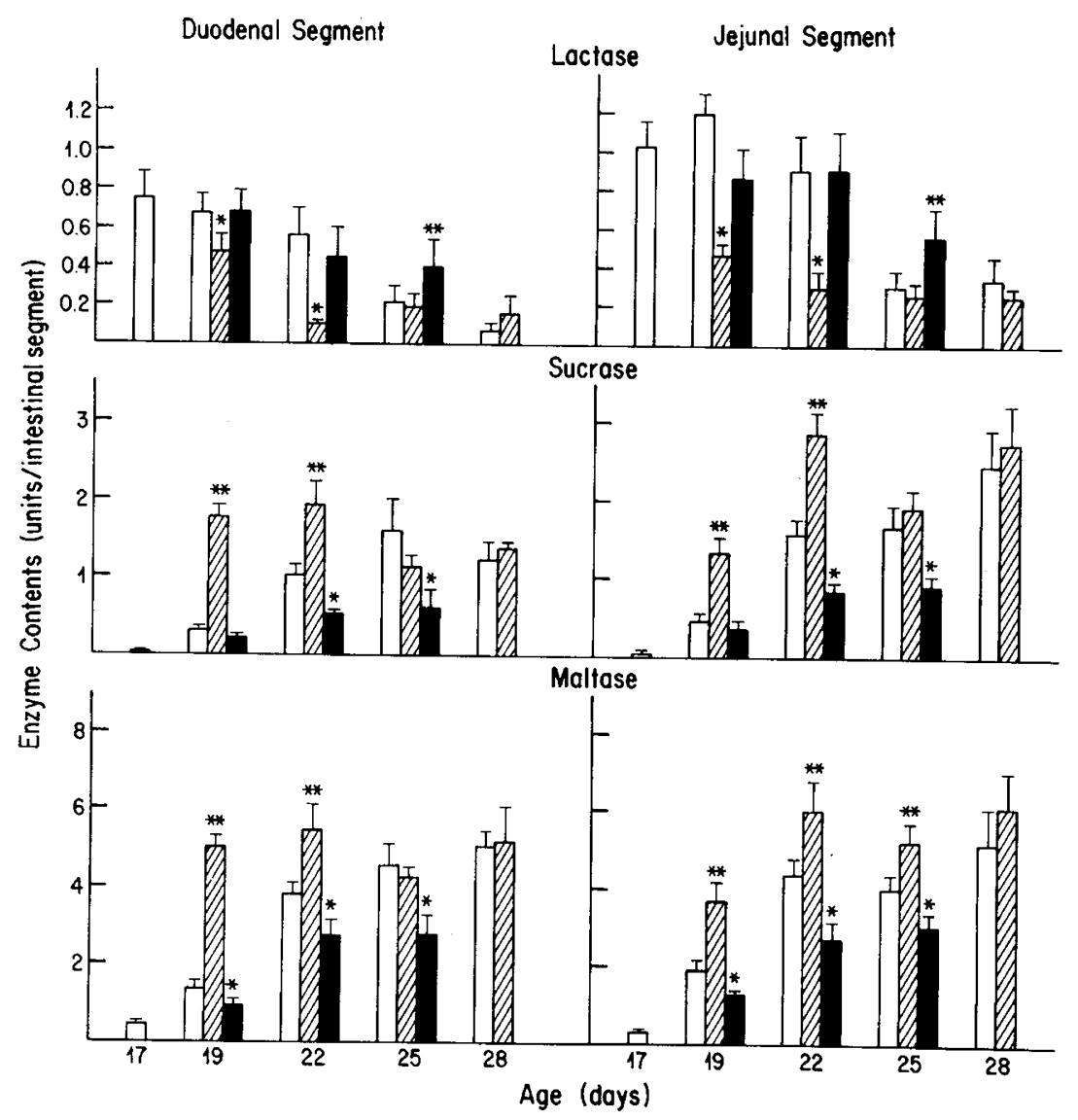

Fig. 3. Effect of early weaning and prolonged nursing on the developmental changes of lactase, sucrase, and maltase contents per segment of small intestine in the duodenal and jejunal region of weaning rats. All symbols are the same as in Figure 1.

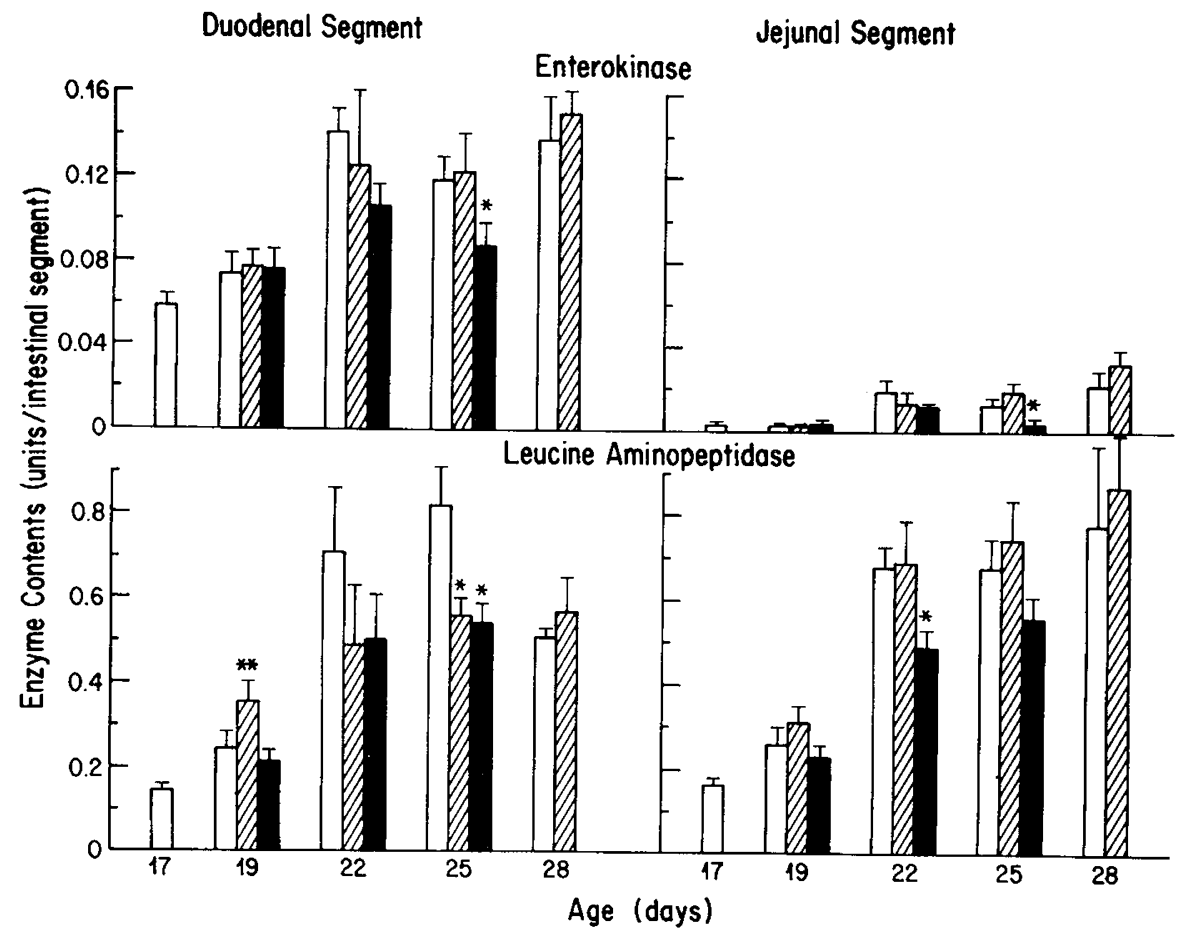

Fig. 4. Effect of early weaning and prolonged nursing on the developmental changes of enterokinase and leucine aminopeptidase contents per segment of small intestine in the duodenal and jejunal region of weanling rats. All symbols are the same as in Figure 1.

may be a result of a dietary shift; however, hormonal changes or inherent programming has also been shown to play important roles in the adaptive changes seen in the small intestine. In this study, we examined the effect of early weanling and prolonged nursing in the development of the small intestine in 17-28-day- old rat pups. Our results support the concept of an interaction among genetic programming, dietary and hormonal, on the development of intestinal enzymes, particularly that of lactase, maltase and sucrase $(6,8,11)$.

Rat milk has lactose as the major source of carbohydrate. In 
Table 2. Effect of early weanling and prolonged nursing on serum corticosteroid levels

\begin{tabular}{lc}
\hline \multicolumn{1}{c}{ Groups $^{1}$} & Corticosterone level $(\mu \mathrm{g} / 100 \mathrm{ml})^{2}$ \\
\hline Control & $4.0 \pm 1.5$ \\
Early weanling & $14.3 \pm 2.1^{3}$ \\
Prolonged suckling & $4.7 \pm 2.1$ \\
\hline
\end{tabular}

${ }^{1}$ Rats were 19-days-old when sacrificed with serum pooled from pups of each group.

${ }^{2}$ Values represent mean \pm S.E.M. of results from three separate experiments.

${ }^{3}$ Significantly higher than control $(P<0.05)$.

comparison, the laboratory chow used at weaning has polymers of glucose and some sucrose as the major carbohydrate components. Early weaning changes the consumption of carbohydrates abruptly from a lactose-containing diet to a sucrose- and glucosepolymers-containing diet. Prolonged nursing, on the other hand, extends the consumptions of the lactose diet. The increase in sucrase and maltase activities in the prolonged nursed pup can be considered as due to inherent programming whereas the precocious increase in sucrase and maltase in early weaned rats may be attributed to dietary influence. The enzymatic changes may be mediated by nutritional and/or hormonal causes. Our results showed that early weaning did not affect the body weight of the rat (Table 1). As demonstrated previously (15), prolonged nursing led to retarded growth that is more likely related to a restricted supply of nutrients rather than to a change in nutrient composition in the diet (i.e., milk versus laboratory chow). Other possibilities include changes in the milk composition, feeding behavior of the pups, decrease milk intake per body weight, and possible hormonal changes.

Early weaning had little effect on the somatic development of the small intestine except for an increase in intestinal length at days 19 and 22 as compared to controls. This increase in intestinal length is particularly interesting. It may represent an adaptation in digestive and absorptive surfaces required for processing the new diet.

The segmental mucosal weight, DNA, and protein contents showed parallel increases in both early weaned and control pups. The comparable increase in mucosal weight, DNA, and protein contents would suggest a preprogrammed control of these parameters rather than a result of dietary changes. The fact that the small intestine of prolonged nursed rats shows similar development of maltase and sucrase activities at day 25 without eating a sucrose- and glucose-polymer-containing laboratory chow also suggests a basically preprogrammed control that cannot be overridden by diets at least of these two disaccharidases in their postnatal development. A similar increase in sucrase is also observed by Henning and Guerin (20) in nonweaned rats at day 28 .

Our results indicate a precocious increase in sucrase and maltase with a corresponding decrease in lactase after early weaning. These changes may be attributed to the consumption of a sucroseand glucose-polymer-containing laboratory chow that is virtually devoid of lactose. A similar precocious increase in sucrase and maltase was also seen in a previous study by feeding sucrose to 9 day-old rats (15). The persistent higher level of lactase in rats undergoing prolonged nursing also confirms our previous report (16) and reaffirms the possible importance of lactose in influencing the developmental pattern of the mucosal lactase in rats. The rat small intestinal mucosa, thus, shows adaptation to dietary changes at day 17 . It is, however, not known whether diet acts directly on the small intestine or indirectly via endocrine factors.

The significant increase in serum corticosteroid levels in early weaned pups together with a superinduction, i.e., induced to a level far higher than obtained in normal development at any age including adults, are important observations in this study. Corticosteroid has been shown to be an inducer for disaccharidase before weaning in mice $(18)$ and rats $(9,12,19)$. The accompanying increase in serum cortisol levels in the early weaned pups suggests a possible involvement of this hormone during the dietary shift in causing precocious increases in sucrase and maltase. The participation of corticosterone in the dietary induction of these enzymes have been shown both in vivo and in vitro. Thus adrenalectomized rats will not respond to sucrose feeding (15) and the sucrosemediated induced appearance of sucrase in cultured intestine are obtained only in the presence of added glucocorticoid (22). A recent report by Boyle and Koldovsky (1) also showed the importance of the adrenal gland in controlling the intestinal "adaptive" response to premature weaning in suckling rats. The present results although did not pinpoint the actual action of cortisol but provide direct evidence for the involvement of this important endocrine factor, i.e., serum cortisol levels in the precocious induction of sucrase and maltase in early weaning of rats.

In summary, the contribution of genetic programming in controlling small intestinal development is reaffirmed. This is illustrated by the parallel increase in the mucosal weight, protein, and DNA content despite the dietary variations. The levels of sucrase, maltase, and lactase show developmental changes on which are superimposed dietary influences as evidenced by the delayed decrease of lactase in the prolonged nursed pups and may also be by the precocious increase in maltase and sucrase in the early weaned rats. Dietary change may be stressful enough to modify the timing in the natural progression of small intestinal ontogeny perhaps through the action of, or in concert with, corticosteroids.

\section{REFERENCES AND NOTES}

1. Boyle, J. T. and Koldovsky, O.: Critical role of adrenal glands in precocious increase in jejunal sucrase activity following premature weaning in rats: negligible effect of food intake. J. Nutr., 110: 169 (1980).

2. Burton, K.: A study of the conditions and mechanism of the diphenylamine reaction for the colorimetric estimation of deoxyribonucleic acid. Biochem. J., 62: 315 (1956)

3. Buts, J. P. and DeMeyer, R.: Postnatal proximodistal developmental of the small bowel mucosal mass in growing rats. Biol. Neonate, 40:62 (1981).

4. Cox, W. M., Jr. and Mueller, A. J.: Composition of milk from stock rats and apparatus for milking small laboratory animals. J. Nutr., 13: 249 (1937).

5. Dahlqvist, A.: Assay of intestinal disaccharidases. Anal. Biochem., 22: 99 (1968)

6. DeRittis, G., Falchuk, A. M., and Trier, J. S.: Differentiation and maturation of cultured fetal rat jejunum. Dev: Biol., 45: 304 (1975)

7. Erlanger, D. F., Kokowski, N., and Cohen, W.: The preparation and properties of two new chromogenic substrate of trypsin. Arch. Biochem. Biophys., 95: 271 (1961).

8. Ferguson, A., Gerskowitch, V. P., and Russell, R. I.: Pre and post-weaning disaccharidase patterns in isografts of fetal mouse intestine. Gastroenterology, 64: 292 (1973).

9. Galand, G. and Forstner, G. G.: Soluble neutral and acid maltases in the suckling-rat intestine. The effect of cortisol and development. Biochem. J., I44: 281 (1974).

10. Goldstein, R., Klein, T., Freier, S., and Menzel, J.: Alkaline phosphatase and disaccharidase activities in the rat intestine from birth to weaning. I. Effect of diet on enzyme development. Am. J. Clin. Nutri., 24: 1224 (1971)

11. Kendall, K., Jumawan, J., and Koldovsky, O.: Development of jejunoileal differences of activity of lactase, sucrase and beta-galactosidase in isografts of fetal rat intestine. Biol. Neonate, 36: 206 (1979).

12. Herbst, J. J. and Koldovsky, O.: Cell migration and cortisone induction of sucrase activity in jejunum and ileum. Biochem. J., 126: 471 (1972).

13. Koldovsky, O. and Chytil, F.: Postnatal development of $\beta$-galactosidase activity in the small intestine of the rat. The effect of adrenalectomy and diet. Biochem. J., 94: 266 (1965).

14. Koldovsky, O.: Developmental, dietary, and hormonal control of intestinal disaccharidases in mammals (including man). In Randle, P. J. et al. Ed.: Vol. III. Carbohydrate Metabolism and its Disorders. pp 482-522 (Academic Press, London, UK, 1981).

15. Lebenthal, E., Sunshine, P., and Kretchmer, N.: Effect of carbohydrate and corticosteroids on activity of $\alpha$-glucosidases in intestine of the infant rat. $\mathrm{J}$. Clin. Invest., 51: 1244 (1972).

16. Lebenthal, E., Sunshine, P., and Kretchmer, N.: Effect of prolonged nursing on the activity of intestinal lactase in rats. Gastroenterology, 64: 1136 (1973).

17. Lowry, O. H., Rosebrough, N. J., Farr, A. L., and Randall, J. J.: Protein measurement with the Folin phenol reagent. J. Biol. Chem., 193: 265 (1951).

18. Moog, F., Denes, A. E., and Powell, P. M.: Disaccharidases in the small intestine of the mouse: Normal development and influence of cortisone, actinomycin D, and cycloheximide. Develop. Biol., 35: 143 (1973).

19. Henning, S. J., Helman, T. A., and Kretchmer, N.: Studies on normal and precocious appearance of jejunal sucrase in suckling rats. Biol. Neonate, 26: 249 (1975).

20. Henning, S. J. and Guerin, D. M.: Role of diet in the determination of jejunal sucrase activity in the weanling rat. Pediatr. Res., 15: 1068 (1981).

21. Raul, F., Simon, P. M., Kedinger, M., Grenier, J. F., and Haffen, K.: Sucrase and lactase synthesis in suckling rat intestine in response to substrate administration. Biol. Neonate, 33: 100 (1978).

22. Raul, F., Kedinger, M., Simon, P. M., Grenier, J. F., and Haffen, K.: Comparative 
in vivo and in vitro effect of mono- and disaccharides on intestinal brush border enzyme activities in suckling rats. Biol. Neonate, 39: 200 (1981).

23. Szasz, G.: A kinetic photometric method for serum leucine aminopeptidase. Am J. Clin. Path., 47: 607 (1967)

24. We thank S. Brooks, B. Krantz, S. Kohut and O. Kim for their skillful technical assistance and Mrs. M. Arseneau for her help in the preparation of the manuscript.
25. Requests for reprints should be addressed to: Dr. P. C. Lee, Division of Gastroenterology and Nutrition, Children's Hospital of Buffalo, 219 Bryant Street, Buffalo, New York 14222.

26. This research was supported in part by NIH grant \#12586.

27. Received for publication March 23, 1982.

28. Accepted for publication December 14, 1982.

Copyright $(\subset 1983$ International Pediatric Research Foundation, Inc. $0031-3998 / 83 / 1708-0645 \$ 02.00 / 0$ 